\begin{tabular}{|l|l|l||}
\hline \multicolumn{2}{|c|}{ PublisherInfo } \\
\hline \hline PublisherName & $:$ & BioMed Central \\
\hline \hline PublisherLocation & $:$ & London \\
\hline \hline PublisherImprintName & $:$ & BioMed Central \\
\hline \hline
\end{tabular}

\title{
Interupted sedation reduces ITU length of stay
}

\begin{tabular}{|l|l|l||}
\hline \multicolumn{2}{|c|}{ ArticleInfo } \\
\hline \hline ArticleID & $:$ & 4210 \\
\hline \hline ArticleDOI & $:$ & $10.1186 /$ ccf-2000-5538 \\
\hline \hline ArticleCitationID & $:$ & 5538 \\
\hline \hline ArticleSequenceNumber & $:$ & 69 \\
\hline \hline ArticleCategory & $:$ & Paper Report \\
\hline \hline ArticleFirstPage & $:$ & 1 \\
\hline \hline ArticleLastPage & $:$ & 3 \\
\hline \hline & & RegistrationDate : 2000-6-27 \\
\hline ArticleHistory & $:$ & OnlineDate \\
\hline \hline ArticleCopyright & $:$ & Current Science Ltd2000-6-27 \\
\hline \hline ArticleGrants & $:$ & \\
\hline \hline ArticleContext & $:$ & 1305422 \\
\hline \hline
\end{tabular}


Mike Grocott, ${ }^{\text {Aff1 }}$

Aff1 University College London Hospitals, London, UK

\section{Keywords}

Mechanical ventilation, midazolam, propofol, sedation

\section{Comments}

This is a well designed study with an outcome that should provoke consideration of the risk/benefit profile of continuous sedative infusions in critical care. The study clearly demonstrates that daily waking and assessment of patients on continuous sedative infusions can result in a reduction in duration of both mechanical ventilation and intensive care unit (ICU) stay. However, overall hospital stay and in-hospital mortality did not differsignificantly between the two groups. Sedation level was assessed usingthe Ramsay score; however, no scores are reported in the paper making itdifficult to assess how much the groups differed in sedation levelachieved. Although reported complications were reduced in the interventiongroup the investigators focussed on events directly attributable to wakefulness (patient removal of endotracheal tube or central venous catheter). They did not address whether other complications (eg cardiovascular instability) or patient distress were more or less frequent with this pattern of sedation.

\section{Introduction}

Continuous sedative infusions are commonly employed in many ICUs; however, their use has been associated with prolonged duration of mechanical ventilation and length of ICU and hospital stay. The study was designed to establish whether the daily interruption of continuous sedative infusions could decrease ICU stay, hospital stay and duration of mechanical ventilation.

\section{Methods}

- A randomised controlled trial of 128 mechanically ventilated adults in a medical ICU 
- Intervention group had sedative infusions stopped until the patient awoke

- Control group had sedative infusions managed according to the attending physicians usual practise

- Patients were further randomly assigned to receive either midazolam with morphine or propofol with morphine

\section{Results}

The intervention group had a reduced median duration of mechanical ventilation days (4.9 vs 7.1 days; $P=0.004)$ and reduced median length of stay in the ICU (6.4 vs 9.9; $P=0.02)$ when compared with the control group. Fewer of the patients in the intervention group had diagnostic tests to assess mental status (6/68 vs $16 / 60 ; P=0.02)$. Daily waking andassesment seems to have reduced the requirement for special tests of brainfunction such as CT. Complications occurred less commonly in the intervention group ( $3 / 68$ vs $4 / 60 ; P=0.88)$.Patients in the intervention group sedated with midazolam received a lower total dose of midazolam $(P=0.05)$ and morphine $(P=0.009)$ than those in the control group. No comparable difference was observed in patients sedated with propafol.

\section{Additional information}

See accompanying editorial by Heffner et al,New Engl J Med 2000, 342:1520-1522

\section{References}

1. Kress JP, Pohlman AS, O'Connor F, Hall JB: Daily interruption of sedative infusions in critically ill patients undergoing mechanical ventilation. N Engl J Med. 2000, 342: 1471-7.

This PDF file was created after publication. 